\title{
Study on the Grouting Pre-Reinforcement Mechanism and Effect Evaluation in Water-rich Loess Tunnel
}

\author{
Xiaohui XUE ${ }^{1, a^{*}}$, Jun ZHANG ${ }^{2, b}$ and Zhongming SU ${ }^{2, c}$
}

${ }^{1}$ Corresponding author, Engineer, Key Laboratory of Highway Construction and Maintenance Technology in Loess Region, Shanxi Transportation Research Institute, Taiyuan, 030006, China.

2 Engineer, Key Laboratory of Highway Construction and Maintenance Technology in Loess Region, Shanxi Transportation Research Institute, Taiyuan, 030006, China.

a582991719@qq.com, b277164704@qq.com, ${ }^{\text {c3 } 375216207 @ q q . c o m ~}$

Keywords: Idea of underground water environmental balance, Water-rich loess tunnel, Grouting pre-reinforcement mechanism, Effect evaluation

Abstract. In order to solve the problem of water-rich loess tunnel in construction process, the paper based on the idea of underground water environmental balance, use the Kuniaki Sato empirical formula and underground runoff modulus to build correlation function, get the permeability coefficient. Then we combine the engineering practice condition of the Qiaoyuan tunnel, use the duplex pipe grouting to reinforce the water-rich loess tunnel, and evaluate the grouting effect. Results show that there are a great lot of obvious grouting veins on tunnel face, and the bedding is clear. There are not bleeding phenomenon on tunnel face. The surrounding rock is stable, no such phenomenon occurred as collapse, instability, gushing water or mud, etc. The soil strength has increase dramatically, and the permeability has reduced significantly. The permeability coefficient of grouting soil meets the requirements of underground water environmental balance.

\section{Introduction}

The loess highway tunnel is becoming more and more numerous with implement of the western de-velopment strategy of China. The tunnel excavation will become groundwater collection galleries in the water-rich loess layer. When the water content of surrounding soil is increasing, and even is reaching saturation, a "slimed" phenomenon has emerged. Its strength and stability decline rapidly. It is prone to lining crack and water leakage in basement uplifts, vault, landslides, and other diseases in the construc-tion of water-rich loess tunnels. It implements "anti-handling combine to row-oriented" principles of go-vernance in traditional drainage method. On the one hand strengthening tunnel waterproof and drainage system to make the lining behind the stagnant water can drain away. On the other hand using "Advanced curtain grouting and blocking water" measures to plug water channels within a certain radius around the tunnel and reduce the effect of underground wa-ter on ecological environment. Loess particles are composed mainly of silt, containing sand and clay. Its loose structure, with the discharge of water be-hind the tunnel lining, soil is constantly being "hol-lowed out", thus forming cavities, threatening the safety of lining structure. The "row-based" measures can not solve water damage of tunnel fundamentally. It easily leads to falling water tables, depletion of surface water and environmental damage. "Advance drapery grouting" reduces the loss of groundwater, but the project cost is bigger and duration is longer. In the process of construction in loess tunnel of rich water, how to take effective measures to protect the groundwater balance and maintain ecological balance, how to keep it low construction cost and short construction period, are major technical challenges currently.

\section{The Concept of Groundwater Balance}

For water-rich loess formations, the recharge of groundwater is the same as its excretion basically be-fore tunnelling. It is in equilibrium. The excavation of the tunnel leads to increasing excretion of groundwater, thus breaking its original equilibrium state. When the amount of groundwater seepage (Qs) is less than the 
groundwater recharge $(\mathrm{Qb})$ within the scope of the impact of the tunnel during construction, environmental damage caused by underground water loss is temporary and reversible.

According to the requirements of groundwater balance concept, it uses "limited emissions, quantita-tive shutoff" principle to deal with groundwater in water-rich loess tunnel construction. It uses appro-priate grouting way by controlling the permeability of the surrounding rock grouting, the amount of water seepage in the tunnel construction will control in less recharge. Thus it can not only protect the eco-logical balance, but also reduce construction costs and shorten the duration of purposes.

\section{The Determination Method of Grouting Permeability Coefficient}

The Prediction of Water Inflow. The Kuniaki Sato method is the most suitable for un-steady state in numerous methods of water inflow into tunnel. The specific relationship of the maximum tunnel water inflow per unit length, normal water inflow and water inflow from the maximum water inflow to water inflow at a certain time $t$ is shown in Figure 1.

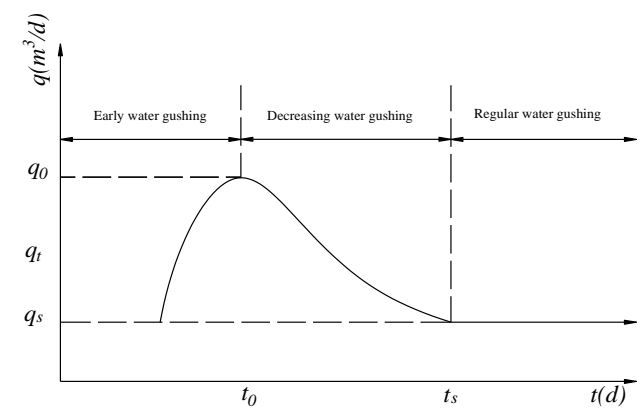

Fig.1 $q$ - $t$ relation curve

From Figure 1, it can be seen that water gushing q0 in the early stages of inflow is the maximum value in the water gushing out, so we should take its value as the representative value in the Grouting rein-forcement design process.

$$
Q_{y}=q_{0}=\frac{1.72 \pi K\left(H-r_{0}\right)}{\ln \left\{\tan \frac{\pi\left(2 H-3 r_{0}\right)}{4 h} \cot \frac{\pi r_{0}}{4 h}\right\}}
$$

$\mathrm{K}$ is the coefficient of permeability, $\mathrm{H}$ is the height from the static water level to the base of the tunnel and $\mathrm{r} 0$ is the tunnel cross section equivalent circle radius, $\mathrm{h}$ is thickness of aquifer.

Calculation of Groundwater Recharge. The basic principle of underground runoff modulus method is groundwater circulation balance. Within a certain range, the complete cycle of surface water keep a balance state. The formulation of water circu-lation balance is:

$$
W=H^{\prime}+h^{\prime}+E
$$

Annual recharge of groundwater $\mathrm{Qb}$ is:

$$
Q_{b}=1000\left(W-H^{\prime}-E\right) F
$$

$\mathrm{W}$ is the average annual rainfall in the area $(\mathrm{mm}) ; \mathrm{H}^{\prime}$ is runoff depth $(\mathrm{mm}) ; \mathrm{H}$ is the annual groundwater runoff depth $(\mathrm{mm}) ; \mathrm{F}$ is surface water drainage area $(\mathrm{km} 2) ; \mathrm{E}$ is surface evaporation this area. Its Calculation can refer to Turk experience formula.

$$
E=\frac{W}{\left[0.9+\frac{W^{2}}{\left(300+25 T+0.05 T^{3}\right)^{2}}\right]^{0.5}}
$$

$\mathrm{T}$ is the average temperature in the region $\left({ }^{\circ} \mathrm{C}\right)$.

3.3 The Determination of Grouting Permeability Coefficient. We should take the factor of safety into account in calculating actual water seepage Qs after tunnel con-struction.

$$
Q_{s}=Q_{y}=\frac{Q_{b}}{k}
$$


The $\mathrm{k}$ is for the safety factor, and the value is 2 to 3 .

It can be deduced grout permeability coefficient $\mathrm{K}$ as follows by equation (5):

$$
K=\frac{581 \ln \left\{\tan \frac{\pi\left(2 \mathrm{H}-3 \mathrm{r}_{0}\right)}{4 \mathrm{~h}} \cot \frac{\pi r_{0}}{4 h}\right\}\left(W-H^{\prime}-E\right) F}{\pi k\left(H-r_{0}\right)}
$$

\section{The Background of Project}

The Overview of Project. The Qiaoyuan tunnel is separated tunnel. The maximum distance between the axis of two holes is $32 \mathrm{~m}$, the design speed is $80 \mathrm{~km} / \mathrm{h}$. The clear width of tunnel construction clearance is $10.25 \mathrm{~m}$, lane is $3.75 \mathrm{~m} \times 2$, limit high is $5 \mathrm{~m}$, the length of each hole is about $1572 \mathrm{~m}, 1626 \mathrm{~m}$. The largest burying depth of cave is $114.98 \mathrm{~m}$. It uses "NATM" in the construction.

The stratigraphic in regional tunnel site from top to bottom is as follows: the quaternary upper pleistocene aeolian sediment $\left(\mathrm{Q}_{3}^{\mathrm{col}}\right)$ and quaternary middle pleistocene drifted material $\left(\mathrm{Q}_{2}^{\mathrm{alppl}}\right)$. The quaternary upper pleistocene aeolian sediment are distributed at the surface of tunnel site, its thickness is $6.0 \sim 12.7 \mathrm{~m}$, its soil is even and structure is loose, vertical joints is developed with the weight of - IV III grade level collapsible.

The situation of tunnel disease. There exit bleeding phenomenon on tunnel face. Water seepage is serious on initial support surface. There is a continuous drip line, accompanying with white crystals. There are many cracks in the invert of the tunnel section and most of the cracks located in the central of invert, along the axial direction toward the tunnel. The maximum width of the crack reaches $1.25 \mathrm{~cm}$. There appear many cracks on Sidewall of two lining part with width of $0.2 \sim 3.0 \mathrm{~mm}$. The specific cases are shown in Figure 2, 3.

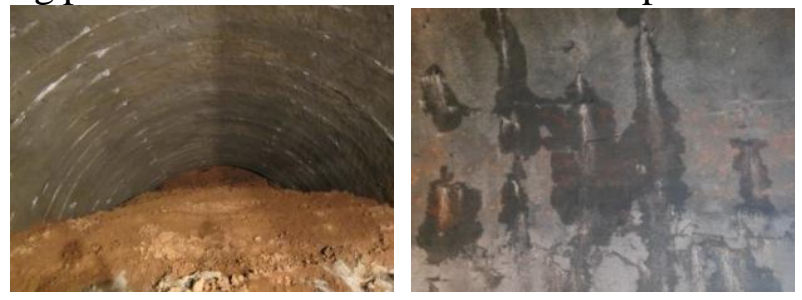

Fig.2 Leakage situation of primary support

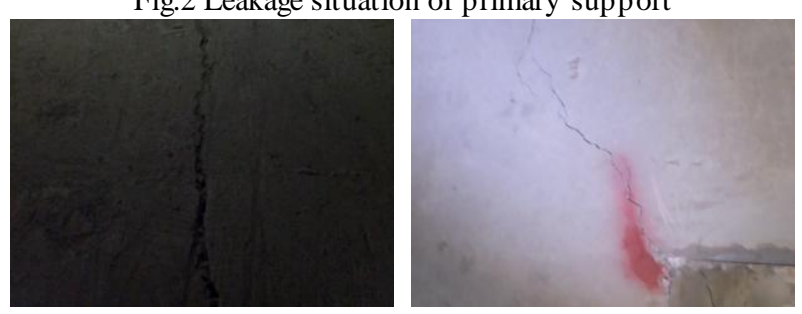

Fig.3 Crack of inverted arch and secondary lining

\section{Grouting Implementation Scheme}

The grouting material. According to the actual conditions, we choice $100 \mathrm{~m}$ tunnel section to be the research objects. The safety factor $\mathrm{k}$ is 2.5 . Using the formula 6 and other parameters, we can get the permeability of grouting to be $7.55 \times 10-6 \mathrm{~cm} / \mathrm{s}$ 。 After a series of contrast tests, we use the A-B slurry, and its mix proportion is shown as following.

A slurry: early strength cement 425 \# $(\mathrm{kg})$ : water $(\mathrm{L})$ : retarder $(\mathrm{L})=1: 1: 0.2$;

B slurry: water glass $(\mathrm{L})$ : water $(\mathrm{L})=1: 1.5$ 。

In the process of grouting, the volume ratio of A-B slurry is 1:1, and the slurry setting time should be controlled to be $40 \sim 50$ s to improve the construction progress.

The grouting borehole design. In this project, we use the horizontal grouting method to reinforce the rock before the tunnel face $10 \mathrm{~m}$. In the excavation contour line, the grouting holes are designed to be cinquefoil. The holes distance is $0.4 \mathrm{~m}$, and the depth is $10 \mathrm{~m}$, the diffusion radius is $1.0 \sim 3.0 \mathrm{~m}$. The specific cases are shown in Figure 4. 


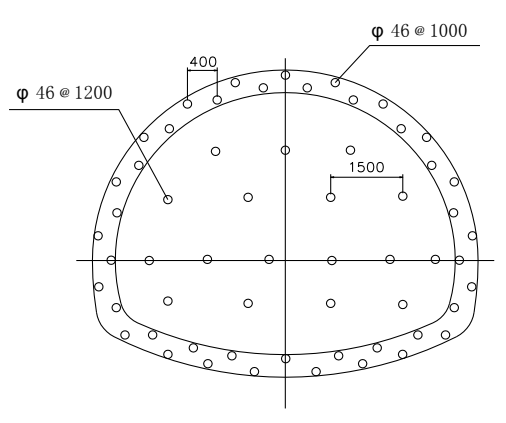

Fig.4 Lay out of horizontal grouting hole

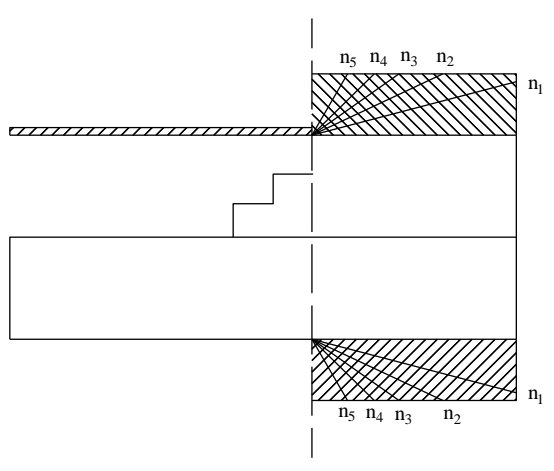

Fig.5 Lay out of radiation grouting hole

In order to form the water-stop collar out the excavation contour line, we should use the irradiation grouting method. The irradiation grouting holes bases on the horizontal holes, and five irradiation holes are arranged to be around the horizontal holes. The specific cases are shown in Figure 5.

\section{The effect evaluation of grouting}

The effect evaluation of horizontal grouting. The soil which is reinforced by horizontal grouting will be exposed in the next circulation. So we can primary judge the effect through the spot observation. The specific cases are shown in Figure 6.
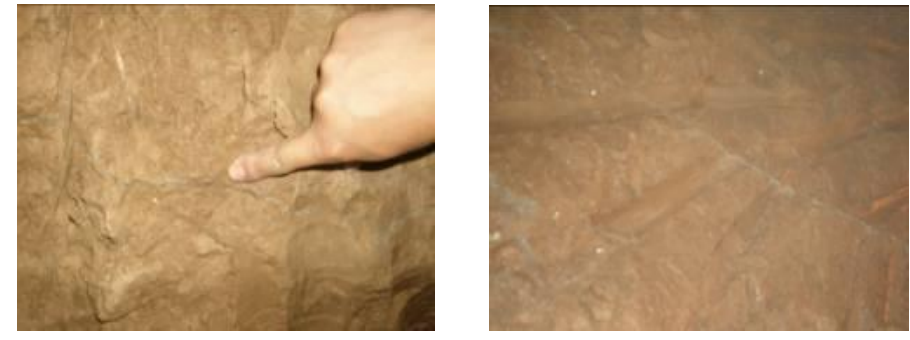

Fig.6 Spot observation of horizontal grouting

From the figure 6, we can get that there are many slurry veins and the bedding distributions are very clear. In the process of construction, there is no phenomenon of water bleeding in tunnel face soil, and the stabilization is good. The soil strength has been improved apparently.

The effect evaluation of irradiation grouting. Firstly, we use the cutting ring to sample in the grouting soil. Secondly, through the falling head permeability test, we can test the permeability coefficient of the sample. Every sample should be tested several times, then we choice the average value to be the result. The results are shown in the following picture.

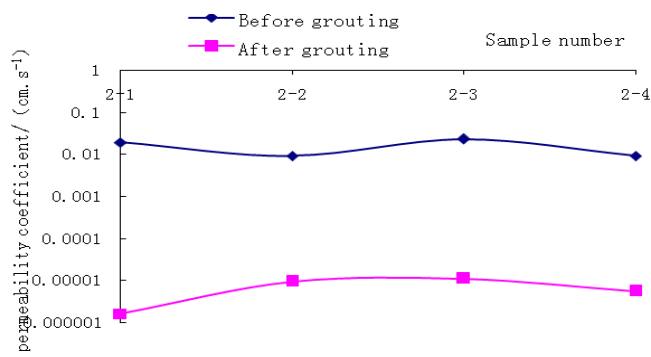

Fig.7 Comparison curve of sample's permeability coefficient

From the picture 7, we can get the conclusion that the permeability coefficient is reduced apparently. In this tunnel face, the permeability coefficient decreases from $0.91 \times 10^{-2} \sim 1.53 \times 10^{-2} \mathrm{~cm} / \mathrm{s}$ to $3.54 \times 10^{-6} \sim$ $1.56 \times 10^{-5} \mathrm{~cm} / \mathrm{s}$. After grouting, there is a great decrease on the permeability coefficient. There is a water-stop collar and its permeability coefficient meets the requirement of underground-water balance. 


\section{Conclusions}

For water-rich loess tunnel, from the protection of groundwater environment point of view, based on the concept of groundwater balance, the use of "limited emissions, quantitative shutoff" principle is a good idea to solve the problem of water-rich loess tunnel waterproofing and drainage.

There are a great lot of obvious grouting veins on tunnel face, and the bedding is clear. There are not bleeding phenomenon on tunnel face. The surrounding rock is stable, no such phenomenon occurred as collapse, instability, gushing water or mud, etc. The soil strength has increase dramatically, and the permeability has reduced significantly. The permeability coefficient of grouting soil meets the requirements of underground water environmental balance.

\section{References}

[1] Fu Gang, Cao Yanping, Zhang Lin. The idea of underground water environmental balance applied to the design of the tunnel under high hydrostatic pressures, Rock and Soil Mechanics, 28 (2007) 474 - 478.

[2] Zhu Dali, Li Qiufeng. Method to predict discharge rate of tunnel, Geotechnical Investigation and Surveying.4(2000)18-22.

[3] Lai Hongpeng, Kang Zuo, Xie Yongli. Grouting Pre-reinforcement Technology fot Metro Tunnel in Loess Strata, China Railway Science, 35(2014) 47 - 53.

[4] Zhang Baoyuan, Ren Jianxi, Wang Bo. Application of Duplex Pipe Grouting for a Subway Tunnel to Traverse Ground Fissures, Modern Tunneling Technology, 46(2009) 94 - 98.

[5] Wang Quansheng, Xiao Hongqu. Technique and Mechanism of Double Vertical Injection Grouting, Chinese Journal of Rock Mechanics and Engineering, 30(2008)536-539. 